\title{
Delegación de tareas médicas a enfermería. ¿Se debe instaurar de rutina en dermatología?
}

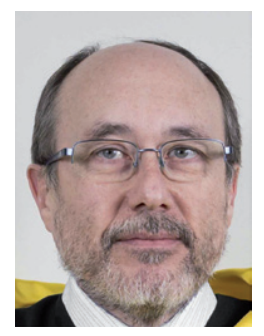

Jesús Borbujo Martínez Jefe del Servicio de Dermatología. Hospital Universitario de Fuenlabrada (Madrid).
En el trabajo cotidiano de una consulta de dermatología, la relación que existe entre el médico y el personal de enfermería es muy estrecha. La confianza entre los dos va aumentando a medida que pasa el tiempo. Llega un momento en que diversas tareas que realiza el dermatólogo las va asumiendo la enfermería de forma paulatina; desde realizar infiltraciones hasta hacer una biopsia con sacabocados $^{1}$.

Pero estas tareas, que se han asumido de forma voluntaria y consensuada entre ambas partes, no se suelen reflejar en un contexto de legalidad. $\mathrm{Y}$ al no existir una certificación académica, tampoco estas tareas tienen una enseñanza específica, ni pueden ser exigibles bajo ningún concepto. Es más, como la enfermería está adscrita a otra dirección en el hospital, poco se puede hacer para que estas tareas se puedan imponer. Y, por último, también va a depender de la opinión de cada dermatólogo o servicio de dermatología el hecho de delegar o no esas actividades, al no existir ningún tipo de obligación al respecto.

En España, existen diversas especialidades de enfermería, entre las que no se encuentra dermatología. Su formación está reglada y asumirán una serie de funciones cuando traba- jen, ya que han sido preparados para ellas y no será una opción voluntarista $^{2,3}$.

Y en dermatología, ¿cómo podemos acreditar y certificar esta delegación de tareas?

En el Hospital de Fuenlabrada, hemos desarrollado esta delegación con el acuerdo de ambas direcciones (médica y de enfermería) con el apoyo del gabinete jurídico y el visto bueno de la dirección de la gerencia.

Como señala la exposición de motivos de la Ley 44/2003 de 21 de noviembre de Ordenación de las Profesiones Sanitarias, es necesario que existan pactos interprofesionales que establezcan las bases para ejercer de forma interdisciplinaria y con competencias y actuaciones compartidas dentro de los marcos de capacitación propios de cada profesión sanitaria.

El ejercicio delegado y el modelo de delegación que hemos protocolizado tiene amparo jurídico material y formal en los artículos 1, 4.7, 7.2 a), 9.3 y 9.4 de dicha ley.

Las técnicas y procedimientos objeto de delegación de este Servicio de Dermatología son: biopsia con sacabocados; electrocoagulación; curetajes; crioterapias; infiltraciones de corticoides y antimoniato de meglumina, previa valoración por un facultativo, quien realizará la prescripción; aten- 
ción a la consulta de terapia fotodinámica y realización de la técnica de cada una de las enfermedades objeto de su atención; atención a la consulta de fototerapia y realización de la técnica denominada fototerapia (cabina con radiación ultravioleta A [UVA] y B [UVB], manos y pies con UVA y UVB y facial con UVA y aplicación de psoraleno tópico $)^{1-6}$.

En cada una de estas tareas que se delegan, se han definido procedimientos de actuación que están revisados y aprobados según un procedimiento de gestión, en el que se detalla claramente $^{5,6}$ :

- Perfil del profesional que va a asumir la delegación en lo que se refiere al problema de salud, procedimiento y/o técnica concretos.

- Descripción de las actuaciones y/o competencias que se delegan.

- Marco y condiciones en los que se va a realizar la delegación.

- Plan de formación con contenidos que incluyan los conocimientos y habilidades que se deben adquirir, y el detalle de los niveles de conocimientos necesarios para su posterior evaluación.

- Sistema de evaluación y revaluación periódica para acreditar el mantenimiento de las competencias adquiridas.

- Rol del profesional responsable de la delegación con sistemática de actuación, especificación de las situaciones en las que debe consultarse al profesional responsable de la delegación por hallazgos o situaciones clínicas no previstas, y supervisión y papel que desarrollar en el proceso de delegación.

- Certificación de la capacitación por parte del profesional responsable de la delegación.

- Firma de aceptación de esta delegación por parte de todos los miembros del servicio.

En el momento actual, después de la buena experiencia de 14 años, se está ampliando la delegación de nuevas técnicas. Sin embargo, se han objetivado en su andadura una serie de problemas que son difíciles de solventar y vienen derivados, casi en su totalidad, de la suplencia de estos profesionales cuando presentan bajas laborales o de otra índole ${ }^{5-7}$.

\section{BIBLIOGRAFÍA}

1. Smith MC. Nursing research: what is it and how can dermatology nurses use it? Dermatol Nurs. 2007;19(5):435-7; quiz 438.

2. Ersser SJ, Kaur V, Kelly P, Langøen A, Maguire SA, Nicol NH, et al. The contribution of the nursing service worldwide and its capacity to benefit within the dermatology field. Int J Dermatol. 2011;50(5):582-9.

3. Kottner J, Surber C. Skin care in nursing: a critical discussion of nursing practice and research. Int J Nurs Stud. 2016;61: 20-8.

4. Courtenay M, Carey N. A review of the impact and effectiveness of nurse-led care in dermatology. J Clin Nurs. 2007;16(1): 122-8.

5. Bobonich M, Nolen M. Competencies for dermatology nurse practitioners. J Am Assoc Nurse Pract. 2018;30(11):606-13.

6. Krensel M, Augustin M, Rosenbach T, Reusch M. Waiting time and practice organization in dermatology. J Dtsch Dermatol Ges. 2015;13(8):812-4.

7. Slade K, Lazenby M, Grant-Kels JM. Ethics of utilizing nurse practitioners and physician's assistants in the dermatology setting. Clin Dermatol. 2012;30(5):516-21. 